\title{
A efetividade do instrumento ZEIS vazias na inserção da Habitação de Interesse Social na cidade planejada: o caso de Brasília
}

The effectiveness of the empty ZEIS instrument in the insertion of Social Interest Housing in the planned city: the case of Brasília

La efectividad del instrumento ZEIS vacío en la inserción de viviendas de interés social en la ciudad planificada: el caso de Brasilia

MELLO, Cristina Maria Correia de ${ }^{1}$ ROCHA, Marecilda Sampaio da ${ }^{2}$ REIS, Talitha Mendes ${ }^{3}$

${ }^{1}$ Programa de Pós-graduação em Arquitetura e Urbanismo, Faculdade de Arquitetura e Urbanismo, Universidade de Brasília, Brasil. Brasília, DF, Brasil. cristina.mello.cmc@gmail.com ORCID: 0000-0003-1153-9899

2 Programa de Pós-graduação em Arquitetura e Urbanismo, Faculdade de Arquitetura e Urbanismo, Universidade de Brasília, Brasil. Brasília, DF, Brasil. mare.sammpaio@gmail.com ORCID: 0000-0001-8181-6316

3 Programa de Pós-graduação em Arquitetura e Urbanismo, Faculdade de Arquitetura e Urbanismo, Universidade de Brasília, Brasil. Brasília, DF, Brasil. talitha.mendes@hotmail.com ORCID: 0000-0002-1391-1132 


\title{
Resumo
}

Este artigo aborda como o instrumento urbanístico denominado ZEIS de vazios vem sendo pensado e implementado na cidade planejada, no caso Brasília - DF. Discute-se sua efetividade em atender a demanda de habitação de interesse social, debatendo sobre os limites e as potencialidades desse instrumento, que surgiu pela necessidade de flexibilização de parâmetros urbanísticos para viabilizar a moradia social. Mas será que isso vem atendendo ao ideal planejado? A utilização de outros instrumentos poderia potencializar os resultados de ZEIS de vazios quando se pensa na inserção de moradias sociais em áreas que garantam o efetivo direito à cidade, com dignidade às famílias, integrando-as ao meio social adjacente a esses núcleos? A metodologia utilizada partiu da revisão bibliográfica sobre o tema, seguido do levantamento de dados históricos e ocupacionais e das ações do poder público para a criação de ZEIS de vazios. Averiguou-se nos estudos se as ações adotadas foram relevantes para suprir a demanda socioespacial e do direito à cidade da população de baixa renda no Distrito Federal. O que se constatou foi a pouca efetividade desse instrumento que, apesar de contemplar a delimitação de algumas áreas no planejamento local, ainda se encontra aquém da demanda de moradia.

Palavras-Chave: ZEIS; habitação de interesse social; instrumentos urbanísticos; direito à cidade

\begin{abstract}
This article discusses how the urban instrument called empty ZEIS has been conceived and implemented in the planned city, in the case of Brasilia - DF. Its effectiveness in meeting the demand for social housing is discussed, debating about the limits and potential of this instrument, which arose due to the need to make urban parameters more flexible to make social housing viable. But has this been meeting the planned ideal? Could the use of other instruments enhance the results of voids ZEIS when considering the insertion of social housing in areas that guarantee the effective right to the city, with dignity for families, integrating them into the social environment adjacent to these nuclei? The methodology used started from the bibliographic review on the theme, followed by the survey of historical and occupational data and the actions of the public authorities for the creation of empty ZEIS. In the studies, it was investigated whether the actions taken were relevant to supply the socio-spatial demand and the right to the city of the low-income population in the Federal District. What was found was the little effectiveness of this instrument, which, despite contemplating the delimitation of some areas in local planning, is still below the demand for housing.
\end{abstract}

Key-Words: ZEIS; housing of social interest; urbanistic instruments; right to the city

\begin{abstract}
Resumem
Este artículo discute cómo el instrumento urbano llamado vacíos ZEIS ha sido concebido e implementado en la ciudad planificada, en el caso de Brasilia - DF. Discute su efectividad para satisfacer la demanda de viviendas de interés social, debatiendo sobre los límites y el potencial de este instrumento, que surgió debido a la necesidad de parámetros urbanos flexibles para hacer viable la vivienda social. ¿Pero ha estado cumpliendo el ideal planeado? ¿Podría el uso de otros instrumentos mejorar los resultados de los vacíos ZEIS al considerar la inserción de viviendas sociales en áreas que garanticen el derecho efectivo a la ciudad, con dignidad para las familias, integrándolos en el entorno social adyacente a estos núcleos? La metodología utilizada comenzó a partir de la revisión bibliográfica sobre el tema, seguida de la encuesta de datos históricos y ocupacionales y las acciones de las autoridades públicas para la creación de ZEIS vacíos. En los estudios se investigó si las acciones adoptadas eran relevantes para satisfacer la demanda socioespacial y el derecho a la ciudad de la población de bajos ingresos en el Distrito Federal. Lo que se encontró fue la poca efectividad de este instrumento, que, a pesar de contemplar la delimitación de algunas áreas en la planificación local, todavía está por debajo de la demanda de vivienda.
\end{abstract}

Palabras-clave: ZEIS; vivienda de interés social; instrumentos de planificación urbana; derecho a la ciudad 


\section{Introdução}

Prevista no Estatuto da Cidade e contemplada em cerca de $80 \%$ dos Planos Diretores aprovados, a ZEIS de regularização ou a de vazios, se constitui em um importante instrumento urbanístico caracterizado por zoneamento delimitado com a finalidade de ampliar a oferta de solo para a habitação social e para promover a integração de assentamentos precários a uma infraestrutura urbana menos desigual, buscando garantir localização adequada para os empreendimentos habitacionais de interesse social mediante regras específicas de urbanização (SILVA e VASCONCELOS, 2016; Lei Federal $\left.n^{\circ} 11.977 / 09\right)$.

O tema se coloca como relevante na medida em que hoje existe uma política habitacional no plano federal (Política Nacional de Habitação - PNH), instituída pelo Ministério das Cidades em 2004, que tem como principal meta garantir à população, especialmente a de baixa renda, o acesso à moradia digna e conta com o instrumento ZEIS de vazio para viabilizar a sua implementação.

Discute-se assim, a efetividade desse instrumento no atendimento à demanda habitacional da cidade de Brasília/DF, observando seus limites e suas potencialidades. Verifica-se ainda a possibilidade da utilização de outros instrumentos que venham a potencializar os resultados da ZEIS de vazio. Buscase saber se a aplicação da ZEIS de vazio no local estudado é capaz de garantir o efetivo direito à cidade para a população de baixa renda.

A metodologia utilizada se iniciou pela revisão bibliográfica, baseada em literaturas atuais sobre o tema, seguidos por levantamento de dados históricos e ocupacionais do território estudado, assim como das decisões tomadas pelo poder público da cidade de Brasília na escolha das áreas destinadas à moradia de interesse social. Posteriormente, buscou-se o processo do surgimento da ZEIS de vazios e assim, se verificou se suas ações estão sendo inibidoras ou promovedoras da problemática socioespacial e do direito à cidade.

Diante do exposto, este artigo visa analisar a utilização do instrumento ZEIS de vazios na inserção da habitação de interesse social, tendo como cenário o Distrito Federal - DF, onde existe a demanda por novas habitações em decorrência de aproximadamente 40 mil novos habitantes no DF a cada ano (CODHAB, 2015). Nesse sentido, se pretende verificar a efetividade do instrumento em atender aos seus objetivos de proporcionar à população mais vulnerável o acesso à cidade e à moradia digna.

A partir dessa introdução, o artigo está estruturado em três seções. Na primeira será feito um apanhado geral da política excludente da moradia de baixa renda e o surgimento das ZEIS. Na segunda seção tratar-se-á sobre as ZEIS de vazios e quais os critérios locacionais para a sua implantação de forma a garantir o direito à moradia e à cidade para a população de baixa renda. Por fim, na terceira parte será analisado como ocorreu a ZEIS de vazios em Brasília/DF, percorrendo-se pelas estratégias utilizadas pelo Plano de Ordenamento Territorial do Distrito Federal - PDOT e pelo Programa de Moradia Habita Brasília.

\section{Política de Moradia e o Surgimento das ZEIS}

Desde meados do século XX, quando iniciaram no Brasil as primeiras ações de políticas públicas sobre o tema, a moradia tem se constituído em uma forte aliada no desempenho da economia das cidades. Devido às políticas urbanas e de habitação constituídas ao longo dos anos e com a intensificação da industrialização no Brasil, ocorreu o aumento da população das cidades e o crescimento das relações econômicas, ocasionando o interesse capitalista no solo e a criação de obstáculos para as oportunidades de conquista da terra pelos mais pobres, dificultando o acesso à moradia e à infraestrutura urbana para essa camada da população. Desse processo resultaram os assentamentos precários, incluindo cortiços, favelas e conjuntos habitacionais irregulares, como forma predominante de moradia popular no Brasil. 
O valor da terra urbana, mais barato nas periferias das cidades do que nas regiões mais centrais, levou à construção de conjuntos habitacionais mais longínquos, induzindo a periferização da população de baixa renda e prosperando práticas elitistas, concentradoras e excludentes que ampliaram o problema da segregação ao longo das últimas décadas (BITOUN; MIRANDA, 2004).

Essas características favoreceram a proliferação de áreas marcadas pela problemática socioespacial, longe dos equipamentos públicos, sem transportes, sem mobilidade, muitas vezes sem infraestrutura básica, com fissuras no tecido urbano provocado pela falta de interação entre os diversos grupos sociais. De acordo com Castells (1978), essa condição gera uma paisagem urbana segmentada e hierarquizada, reforçando-se ainda mais essa característica quando o tipo e o nível de equipamentos urbanos implantados nesses locais são disponibilizados de acordo com o nível de renda dos sujeitos moradores e/ou usuários desses respectivos espaços. Segundo Harvey (1977), a segregação socioespacial nas cidades pode ser encarada como o resultado de um processo de produção do espaço citadino seletivo, no qual as diferenças de renda exercem papel decisivo. Conforme Castells (1978), a segregação socioespacial não é fruto de um processo desprovido de intencionalidade.

Muito se tem escrito sobre a problemática da segregação socioespacial das cidades citando sua influência para a habitação social (CORRÊA, 2005; CASTELLS, 1978; BITOUN e MIRANDA, 2004; MARICATO, 2011) e, ao longo do tempo, os diferentes governos brasileiros buscaram solucionar o problema da necessidade da moradia para a baixa renda, sem muito sucesso, no combate à periferização e à exclusão social.

As condições para a possível reversão desse quadro começaram a se formar a partir do contexto da Redemocratização, com o Movimento Nacional de Reforma Urbana que contribuiu para a aprovação do capítulo de Política Urbana da Constituição Federal de 1988 e, posteriormente, do Estatuto da Cidade, trazendo para o contexto brasileiro, o Direito à Cidade. Com esses instrumentos, o Estado em busca de políticas públicas de habitação que visassem inserir a população mais vulnerável à urbe, garantindo o direito à moradia e à cidade para todos os cidadãos, criou o Instrumento Jurídico denominado Zona Especial de Interesse Social - ZEIS.

As ZEIS são instrumentos urbanísticos caracterizados por zoneamentos delimitados com a finalidade de ampliar a oferta de solo para a habitação social e promover a integração de assentamentos precários a uma infraestrutura urbana menos desigual, buscando garantir localização adequada para os empreendimentos habitacionais de interesse social (SILVA e VASCONCELOS, 2016).

A primeira experiência de ZEIS ocorreu em Recife-PE na década de 1980, após um longo processo de lutas sociais com a presença dos movimentos de moradia que buscavam o direito à cidade por meio de uma pauta de reivindicações marcada principalmente pelas questões fundiárias. $O$ direito à cidade pode ser entendido como direito à terra urbana, à moradia, ao saneamento ambiental, à infraestrutura urbana, ao transporte e aos serviços públicos, ao trabalho e ao lazer, para as presentes e futuras populações. (Lei $n^{\circ} 10257 / 01$ - Estatuto da Cidade). Tais lutas entraram em confluência com o aumento da demanda por moradias e infraestrutura urbana e trouxe à tona a necessidade de se buscar alternativas à construção de grandes conjuntos habitacionais que ocorreram na era do BNH e aos programas de remoção de favelas da década de 1970.

Nesse contexto, surge em 1983, na Lei de Uso e Ocupação do Solo do município de Recife, a ZEIS, que delimitou áreas urbanas caracterizadas como assentamentos habitacionais surgidos espontaneamente e já consolidados e estabeleceu normas urbanísticas diferenciadas com a intenção de promover a sua regularização e a sua integração na cidade, levando em consideração o interesse social. A sua regulamentação ocorreu em 1987 por meio do Plano de Regularização da ZEIS PRAZEIS, elaborado com ampla participação social, que se transformou em referência para todo o país na busca da viabilização da urbanização e regularização de áreas ocupadas por assentamentos 
precários (LOSTÃO, 1991).

O município de Belo Horizonte, em 1985, é exemplo de cidades que seguiram o modelo do instrumento PRAZEIS, buscando viabilizar juridicamente a urbanização e regularização de áreas já ocupadas por populações de baixa renda dispostas na cidade de forma irregular - ZEIS de regularização (MIRANDA e MORAES, 2007).

Tradicionalmente no Brasil, o acesso à terra bem localizada e dotada de serviços e infraestrutura era restrito às famílias de maior renda, criando barreiras para a população menos abastada à cidade formal, expulsando-as para as franjas da cidade e proporcionando o crescimento da cidade informal. Nesse padrão, a busca pela aprovação de ZEIS em vazios urbanos visando áreas mais adequadas urbanisticamente para a construção de novas moradias populares, encontraram forte resistência dos grupos conservadores (MIRANDA e MORAES, 2007). A ZEIS de vazios somente veio a ocorrer em 1994, na cidade de Diadema - SP, após um coeso movimento de moradia que contou com o apoio e vontade política do Município para enfrentar as questões sociais e urbanísticas da cidade. Nessa oportunidade se aprovou no Plano Diretor local a delimitação de terrenos particulares não edificados, subutilizados ou não utilizados, para a implantação de empreendimentos habitacionais de interesse social, as ZEIS de vazios.

Apesar da especificação das ZEIS nessas cidades, somente em 1999, com a Lei n 9785/99 foi estabelecido redução de exigências para o caso de parcelamentos situados em áreas de interesse social, permitindo alterações na Lei de Uso e Ocupação do Solo (Lei n 6766/79) e em 2001, com o Estatuto da Cidade e inclusão das ZEIS nos instrumentos de política urbana, elas tornaram-se o principal instrumento de política habitacional, necessariamente contempladas nos Planos Diretores por estarem sujeitas a regras específicas de zoneamento, possibilitando a criação de ZEIS tanto de regularização quanto de vazios. Cabe destacar que a legislação federal não diferencia os tipos de ZEIS, deixando aos municípios responsáveis por sua criação e aplicação.

A regulamentação e aplicação do Instrumento ZEIS é de responsabilidade dos municípios, baseadas no Plano Diretor. Questões importantes ligadas aos procedimentos de implantação, delimitação e instrumentos de gestão dessas áreas são remetidas à esfera municipal, sendo o Plano Diretor o principal instrumento para a realização do referido zoneamento (MARICATO, 2011).

Atualmente, apesar das ZEIS estarem presentes nos Planos Diretores da maioria dos municípios, elas têm sido aplicadas de forma pontual pelos órgãos responsáveis pela política de habitação e/ou desenvolvimento urbano do município e muitas vezes não contam com a participação ativa da sociedade nas suas decisões. Principalmente nas disposições para a criação das ZEIS de vazios, as tipologias habitacionais e a demarcação da área são propostas pelo município de forma top down, sem participação ativa da população, muitas vezes sem o atendimento na íntegra dos seus anseios de moradia. Ressalta-se ainda a necessidade da aplicação das regras das ZEIS de vazios combinada com outros instrumentos do Estatuto da Cidade, mediada pelo poder público e instância participativa, de forma a viabilizar as ZEIS de vazios.

Nesse contexto, temos dois tipos de ZEIS instituídas: a de regularização e a de vazios. Para Paula (2018), o que diferencia as ZEIS de regularização, das ZEIS de vazios consiste no fato motivador de sua criação, ou seja, enquanto que no caso da primeira o princípio norteador é baseado em uma ação corretiva, no caso da segunda o enfoque é preventivo - "ainda que venham a reboque dos problemas habitacionais." Ressalta-se ainda que, conforme afirma a autora, outra questão relevante consiste na vinculação obrigatória das ZEIS de vazios ao uso específico para habitação de interesse social.

Neste artigo, iremos focar apenas nas ZEIS de vazios, uma vez que esse tipo de instrumento possibilita a inserção de novos empreendimentos destinados à população carente que já nasceriam 
regularizados e inseridos no contexto das cidades, resultando assim em um planejamento prévio e não apenas uma medida mitigadora para contornar uma situação indesejável, implementada à revelia do poder público local, como no caso das ZEIS de regularização.

\section{As ZEIS de vazio}

Segundo Lefebvre (2001), a urbe, enquanto centro da vida social e política, deve ser desfrutada por todas as classes da população, onde o direito à cidade é um movimento em direção à constituição de uma democracia concreta. Esse conceito, a partir de fundamentos diversos da temática habitacional, corrobora para a ideia de utilização do instrumento ZEIS a fim de permitir a inclusão da população de baixa renda na cidade.

As ZEIS, definida pela Lei $n^{\circ} 11.977 / 2009$, que dispõe sobre o Programa Minha Casa Minha VidaPMCMV, como: "parcela de área urbana instituída pelo Plano Diretor ou definida por outra lei municipal destinada predominantemente à moradia de população de baixa renda e sujeita a regras específicas de parcelamento, uso e ocupação do solo" (artigo 47, V), foi instituída com o objetivo de garantir localização adequada para os empreendimentos habitacionais de interesse social. A sua demarcação, que pode ser tanto em terrenos ou glebas urbanas, quanto em edificações, é feita pelos municípios, uma vez que estes entes conhecem melhor o território e, portanto, tem melhores condições de contemplar as reais necessidades da população local.

Considerando a ZEIS de vazios, tem-se uma categoria específica de zoneamento da cidade, permitindo a aplicação de normas especiais de uso e ocupação do solo para áreas ou edificações vazias, que não estão cumprindo com a sua função social. Ela considera o processo econômico que excluiu os mais pobres do direito à moradia e, assim, estabelece um plano de urbanização que leva em conta as especificidades sociais, transferindo, inclusive, recursos financeiros prioritariamente para essas áreas (SAULE JÚNIOR, 2004).

Para que se atinja a efetividade desejada nessas áreas, se deve buscar abranger áreas urbanas centrais já consolidadas, públicas ou privadas, ou terrenos e imóveis vazios, subutilizados ou não utilizados, adequados para a produção de habitação de Interesse Social e inseridos na cidade formal. Devem seguir os Planos Locais de Habitação de Interesse Social (PLHIS) ou, caso o município não o possua, seguir critérios pré-estabelecidos para ajudar na seleção das áreas.

Segundo Mello e Bezerra (2019), existem alguns critérios locacionais que devem ser considerados para que a ZEIS de vazio se constitua numa reserva de terras que permita uma boa distribuição sócio espacial para a habitação de baixa renda. São elas: (1) Áreas vazias ou subutilizadas dispondo de infraestrutura e equipamentos públicos adequados; (2) Áreas compatíveis e de fácil integração às condições existentes no entorno com certa centralidade dentro da estrutura da cidade; (3) Terrenos sem restrições à ocupação e à regularização; (4) Diversidade de usos, parcelamento com variedade de formas e dimensões que possibilitem o mix social; (5) Autonomia na determinação de regras de parcelamento, uso e ocupação do solo compatíveis com habitação de interesse social; (6) Áreas demarcadas com porcentagem mínima de áreas destinadas à HIS variando de 70 a 80\%; (7) Conexão com o transporte púbico.

Esses critérios locacionais contribuem, de forma a garantir, não só a unidade habitacional, mas a moradia, no conceito amplo de direito à cidade. É importante observar que a criação de ZEIS de vazios, apesar de incorporada na legislação urbanística das cidades, na prática ainda não possuem uma demarcação precisa das suas áreas. A maior parte das cidades estabelece como ZEIS as áreas já ocupadas pela população de baixa renda e destinadas à regulação fundiária. As ZEIS de vazios, em grande parte dos casos, ainda aguardam regulamentação e maior investimento dos municípios na gestão do instrumento. 
Segundo nos relata Santoro (2015), para que a demarcação de ZEIS possa ocorrer em áreas centrais, é preciso enfrentar uma questão bastante difícil na sua viabilização, que consiste na constatação de que essas áreas são mais valorizadas, apresentando normalmente altos preços, dificultando a sua aquisição pelo poder público. Nesse sentido, o autor aponta ainda que, mesmo essas áreas sendo obtidas, é relevante a dificuldade de famílias carentes contempladas com imóveis neste local se manterem lá, uma vez que, ficam sujeitas à pressão imobiliária para que vendam suas propriedades obtendo algum lucro e retornem para áreas periféricas, onde os terrenos são mais baratos. Isso, em última análise, reforça o velho modelo "centro-periferia", distanciando a "lógica do mercado" da "lógica das necessidades habitacionais", ainda que diminua algumas unidades da conta final.

\section{As ZEIS de vazios em Brasília/ DF}

No desenvolver da história de Brasília se fez presente uma política de segregação socioespacial onde o "operariado" passou a ser instalado distante do Plano Piloto. Apesar da concepção de Lúcio Costa de possuir áreas destinadas a trabalhadores com menor renda no Plano Piloto, acabou por existir uma seletivização espacial, sendo caracterizado como o espaço urbano destinado ao funcionalismo público federal e às classes mais abastadas da sociedade, enquanto as cidades satélites, atuais Administrações Regionais, foram formadas a partir da pressão exercida pelos trabalhadores menos qualificados (CAMPOS, 1988). Peluso (2003) descreveu essa situação:

No espaço finito e fechado do Plano Piloto, envolto por extensas áreas verdes de posse do governo, estava tudo que era necessário para o bem estar de seus moradores e para a função da capital Federal. As mazelas dos grandes centros seriam afastadas dessa cidade burocrática, tranquila $\mathrm{e}$ planejada. Encarregado de não permitir deturpações no Plano, a administração garantiria a equidade, a beleza e a harmonia, atuando neutra e racionalmente (PELUSO, 2003).

Os trabalhadores dos canteiros de obra e os moradores das favelas localizadas nas proximidades do Plano Piloto foram removidos e instalados nas Cidades Satélites, novas áreas criadas para abrigá-los, distantes geograficamente do Plano Piloto. Outras remoções de assentamentos e favelas foram executadas ao longo da formação de Brasília, transferindo-as para as cidades satélites já criadas ou criando novas cidades. A transferência se dava a partir da doação de lotes com o mínimo de infraestrutura, satisfazendo as exigências e necessidades do mercado imobiliário e da elite local, dificultando ou banindo a inserção social desses cidadãos de baixa renda na área central da cidade, o Plano Piloto (GOUVÊA, 1995).

Criou-se assim, entre as Cidades Satélites e o Plano Piloto enormes vazios, marcados entre si pela grande segregação socioespacial, com a implantação de vários loteamentos distantes do centro urbano detentor de empregos e serviços e dotados de infraestrutura. As cidades criadas eram distantes, sem infraestrutura básica, sem serviços e lazer e péssima mobilidade, contribuindo para a degradação socioespacial da população de baixa renda, modelo que se propaga até os dias atuais.

Atualmente a maioria da população reside nos núcleos urbanos criados pela política de erradicação de favelas, onde, muitas famílias apresentam necessidades habitacionais. Diariamente, a maioria dessa população é obrigada a se deslocar por grandes distâncias enquanto os internúcleos, que provocam estes desequilíbrios, permanecem desocupados (GOUVÊA, 1995).

As necessidades habitacionais são espelhadas no déficit habitacional (necessidade de novas moradias) e na inadequação de moradias (precariedade da moradia já existente). Para o provimento de novas áreas habitacionais, como no caso de ZEIS de vazios, ponderamos a importância do déficit habitacional que é composto pela soma de 4 componentes: domicílios precários, coabitação, ônus 
excessivo com aluguel e adensamento excessivo. Em Brasília, o déficit habitacional atinge mais de 129 mil famílias (Fundação João Pinheiro, 2017) e a busca por novas áreas habitacionais para a população de baixa renda é de suma importância.

Conforme nos informa a Secretaria de Estado de Desenvolvimento Urbano e Habitação do Distrito Federal - SEDHAB (2012), a habitação de interesse social no Distrito Federal acompanha a Capital Federal desde sua fundação, oportunidade na qual foi criada a Sociedade de Habitações Econômicas de Brasília - SHEB (1962), sobrevindo na sequência a Sociedade de Habitação de Interesse Social SHIS (1964), que atuou no DF até 1994, quando foi criado o Instituto de Desenvolvimento Habitacional do Distrito Federal - IDHAB. A partir de 2007 até os dias atuais quem assumiu esse papel foi a Companhia de Desenvolvimento Habitacional do Distrito Federal - CODHAB.

A lista de famílias de baixa renda inscritas na lista da CODHAB, interessados em moradia em Brasília, transpassa o número de habitações disponíveis, como pode ser observada pelo tamanho do déficit habitacional. Em 2020 a demanda por unidades habitacionais na lista da CODHAB encontra-se na faixa de 101.400 mil famílias, distribuídas entre as 5 faixas de renda, sendo mais de 58 mil famílias da faixa 1 (até 3 salários mínimos) (CODHAB, 2020). Sendo assim, busca-se novas áreas habitacionais que possam abrigar essa população não só no seu direito básico de moradia, mas também no direito de acesso à cidade.

O instrumento ZEIS busca a inclusão da população de menor renda no direito à cidade e à terra urbanizada, aumentando a oferta habitacional de interesse social, reconhecendo o direito à moradia $\mathrm{e}$ impedindo remoções na área delimitada. Em Brasília, no Plano Diretor de Ordenamento Territorial PDOT 2009 foram previstas 24 áreas para provimento habitacional, dentre as quais 17 não estão ocupadas, e definidas 135 áreas de interesse social, todas voltadas para a regularização de áreas, sendo 113 Áreas de Regularização de Interesse Social - ARIS e 22 de Parcelamento Urbano Isolado PUI. Cita ainda que novas ZEIS poderão ser estabelecidas mediante lei específica (PDOT, 2009, Art.43 V).

A demanda por novas moradias continua sendo uma necessidade e é almejada pela população e lideranças de movimentos de moradia de Brasília. Em 2016, no âmbito da política habitacional do Distrito Federal foi instituído pelo Decreto $\mathrm{n}^{\circ} 37.438 / 2016$ o Programa Habita Brasília que trabalha a partir de três grandes eixos: provimento habitacional, a regularização fundiária e o combate à grilagem, buscando ações interligadas entre 0 processo de oferta habitacional e regularização fundiária (SEGETH, 2017).

O Habita Brasília recomenda a priorização da implantação de moradias dignas, próximas aos centros de emprego, em áreas dotadas de infraestrutura e acesso a serviços e equipamentos públicos. As áreas destinadas ao Programa Habitacional são públicas, provenientes da Companhia Imobiliária de Brasília - TERRACAP, empresa pública do Governo do Distrito Federal - GDF que tem como objetivo a execução, mediante remuneração, das atividades imobiliárias de interesse do DF. A TERRACAP disponibilizou 10 áreas para o provimento habitacional de interesse social dentro do Programa Habita Brasília.

Considerando como estudo os exemplos das ZEIS do Distrito Federal - DF conforme Lei Complementar no 129/2017, que versa sobre a criação de Áreas de Regularização de Interesse social e Zonas Especiais de Interesse Social, observamos a seleção de 10 áreas, ainda não ocupadas, dispostas em várias localidades do DF, com capacidade para atendimento de aproximadamente 21 mil famílias (SEGETH, 2017), conforme Figura 1. Cabe salientar, no entanto, que o déficit habitacional do DF conforme dados da CODHAB, gira em torno de 101 mil unidades, sendo que destas, cerca de 50 mil famílias são de baixa renda, que ganham até 3 salários mínimos. Nesse sentido é interessante observar que, mesmo se todas as ZEIS demarcadas fossem ocupadas, ainda assim cobririam cerca de 
$42 \%$ da necessidade de habitação de interesse social.

É importante levarmos em consideração que, conforme nos aponta Villaça (2001), as cidades tendem a se espraiar conforme vetores que se deslocam nos sentidos oferecidos pelas rodovias existentes, haja vista a questão da mobilidade oferecida. A evolução urbana do DF também acompanha essa tendência e seria razoável supor que as áreas de ZEIS de vazios também assim o fossem, porém isso não é percebido no planejamento dessas áreas.

Figura 1: Mapa de conectividade. Áreas do Habita Brasília para criação de ZEIS de vazios.



Fonte: SEGETH, Zonas Especiais de Interesse Social para provimento habitacional, 2017 - com adaptações

Por outro lado, no DF existem uma gama de lotes vazios sem qualquer tipo de ocupação ou ainda subutilizados, especialmente no Plano Piloto de Brasília. Esse é o caso por exemplo do Setor Hoteleiro Sul - SHS, conforme pode ser visualizado no Geoportal - portal disponibilizado pela antiga SEGETH, atual SEDUH - Figura 2.

Figura 2: Lotes vazios na Quadra 2 do Setor Hoteleiro Sul - SHS.



São lotes que há décadas aguardam uma utilização e que pela legislação atual, se destinam na sua maioria à atividade de hotelaria. Considerando-os como exemplo e ponderando que o tombamento do Plano Piloto de Brasília é urbanístico, observamos que esses lotes até o momento não vêm cumprindo sua função social, conforme determinado no Estatuto das Cidades. Assim, tais lotes sem utilização ou subutilizado poderiam ser pensados para moradia de interesse social, desde que mantivessem as 
normas de gabarito gerais, tais como: altura, taxas de ocupação e construção entre outras, e atingissem os critérios locacionais citados.

Esses lotes desocupados prejudicam a cidade e tornam a infraestrutura urbana subutilizada, trazendo mais custos à sociedade como um todo. Como esse exemplo, existem inúmeros lotes que aguardam utilização no DF, sendo assim, por que não repensar as normas atuais, uma vez que a cidade é "viva" e precisa atender ao seu usuário final, ou seja, o cidadão? Conforme levantado por Moraes (2018), existem 2.697 lotes subutilizados no Distrito Federal que juntos somam 2437,35 ha e 22.456 lotes vagos perfazendo um montante de 2867,95 ha. Nesse sentido, a autora pondera que muito embora 0 quantitativo de lotes vagos seja superior ao número de lotes subutilizados, a diferença de áreas entre eles não é representativa, o que denotaria que os lotes vagos apresentam áreas menores - Figura 3.

Figura 3: Mapeamento dos lotes regulares ocupados, vagos e subutilizados no Distrito Federal

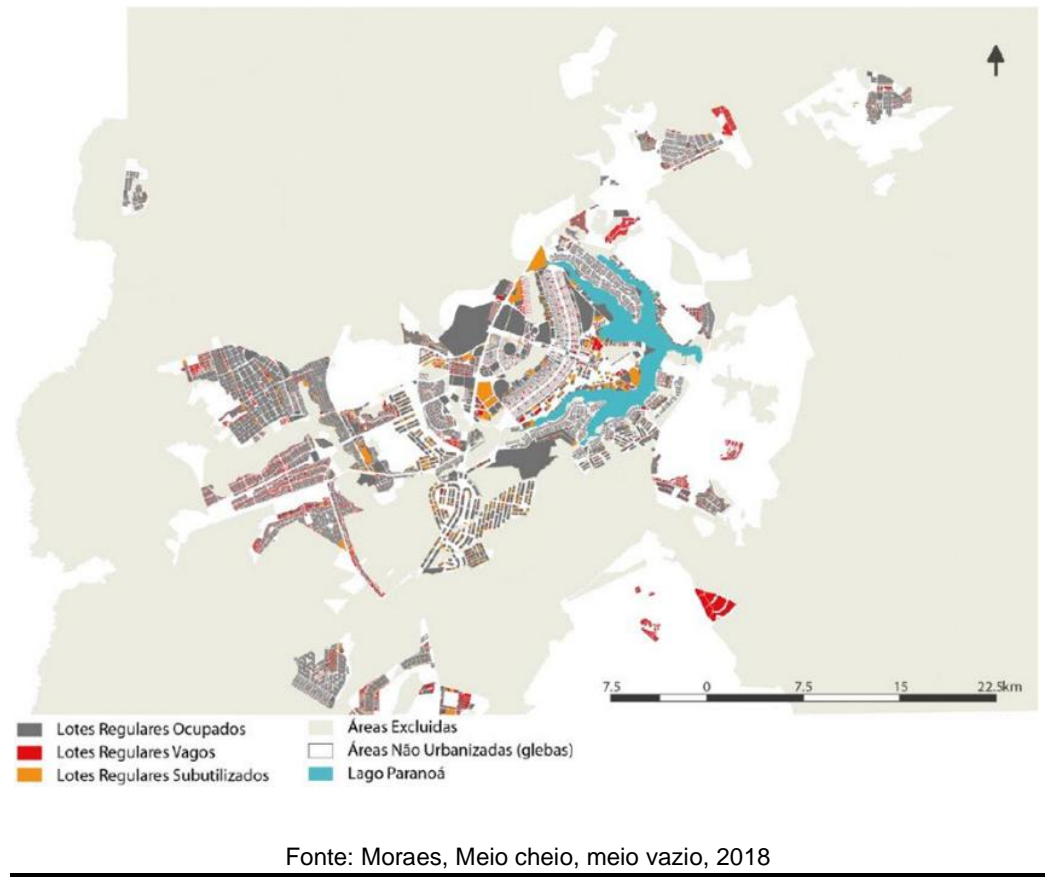

É importante levar em consideração que, no caso empírico do Distrito Federal percebemos que não estão presentes outros instrumentos apresentados pelo Estatuto das Cidades que poderiam auxiliar na criação e implementação das ZEIS, tais como o Parcelamento, Edificação e Utilização Compulsórios PEUC; o Direito de Preempção; o Imposto Predial e Territorial Urbano - IPTU - Progressivo no Tempo ou ainda a Desapropriação do Imóvel com Pagamento em Títulos da Dívida Pública, muito embora tenham sido previsto no PDOT, na prática não são utilizados.

Outro fator relevante a ser considerado consiste na análise do entorno das poligonais destinadas à habitação e criação das ZEIS em relação a sua proximidade com o tecido urbano existente, a presença de infraestrutura e a proximidade de centralidades. O que, via de regra podemos observar é que ocorre uma baixa integração nas áreas selecionadas com as cidades já existentes. Sendo assim, se deve levar em consideração esses fatores como forma de proporcionar melhores ZEIS na cidade.

Nesse sentido, Paula (2018) reitera o conceito de que moradia não pode estar restrito apenas a unidade habitacional, mas sim deve considerar outros aspectos relevantes à dignidade e à qualidade de vida, tais como acessibilidade e acesso a outras atividades necessárias e complementares ao 
habitar - como trabalho lazer e cultura, sem que isso se reflita em comprometimento dessas atividades em decorrência de custos da habitação. Assim, há que se pensar que tipo de habitação social queremos para nossas cidades. ZEIS de vazios deslocadas de maior integração com a cidade não atingem sua função, perdem seu sentido e podem ter efeito desastroso no local, transformando áreas em "guetos" sociais.

\subsection{As Estratégias do PDOT}

No Plano Diretor de Ordenamento Territorial do Distrito Federal - PDOT (LC n803/2009, atualizado pela LC n854/2012), são definidos os dois tipos de Zonas Especiais de Interesse Social: as ZEIS para fins de regularização, as chamadas Áreas de Regularização de Interesse Social - ARIS e as ZEIS de Provisão Habitacional de Interesse Social - objeto deste artigo.

Além da definição de algumas áreas para ZEIS, também encontramos dispositivos relacionados à criação dessas áreas. Neles são estabelecidos parâmetros urbanísticos mais flexíveis para a implantação de ZEIS, tais como: a dispensa do percentual mínimo de $15 \%$ de áreas para equipamentos urbanos comunitários e os espaços livres de uso público, o que, se por um lado favorece a aprovação de novos loteamentos de interesse social, por outro lado, traz à tona a questão recorrente quanto a falta de qualidade dos espaços comuns nos referidos assentamentos.

Nesse contexto, os lotes de ZEIS também estão isentos de atender a área mínima de $125 \mathrm{~m}^{2}$ e $5 \mathrm{~m}$ de testada determinados pela legislação de Parcelamento do solo Urbano ( Lei $n^{\circ} 6.766 / 1979$ ), o que pode levar ao atendimento da demanda de ZEIS de regularização, mas que também podem definir espaços insuficientes para as demandas de uso das famílias favorecidas.

Em sua Seção V, "Da Estratégia de Oferta de Áreas Habitacionais", o PDOT traz uma listagem de áreas, detalhadas em seu Anexo II, Mapa 2 e Tabela 2D, "voltadas à formulação de programas de habitação social" - Figura 4. Nesse sentido, nos aponta Moraes (2018), que a estratégia de Habitação e regularização do PDOT, muito embora utilize áreas vazias e subutilizadas com vistas à inclusão social, diminuindo desigualdades e minimizando a segregação socioespacial, se deve ficar atento para que tal política não acabe tendo resultado oposto ao desejado com a especulação imobiliária encarecendo o preço da terra e desvirtuando a necessidade social premente, o que pode acarretar um subaproveitamento da infraestrutura urbana montada.

Para que essa política possa realmente ser implementada com mais força, caberia ao Estado aplicar outros instrumentos urbanístico já previstos no PDOT como é ocaso do PEUC, IPTU Progressivo no Tempo e a Desapropriação do Imóvel com Pagamento em Títulos da Dívida Pública, porém esses instrumentos nunca foram utilizados no DF. A pergunta que fica é: Por que não? Quais as amarras prendem o Poder Público o impedindo de agir? Essa é uma discussão que a sociedade deve enfrentar com vistas a atingir o bem-estar geral.

$\mathrm{Na}$ continuidade de sua análise, a autora esclarece que o diálogo do PDOT com esses instrumentos que objetiva promover a ocupação de imóveis não edificados, não utilizados e subutilizados, não efetivamente ocupados, na Zona Urbana do Conjunto Tombado e na Zona Urbana Consolidada são contraditórios pois, o mesmo Plano Diretor apresenta uma zona de expansão urbana às bordas do perímetro urbano, disponibilizando uma grande quantidade de terra urbanizável na periferia, em geral mais barata. Isso acaba, de certa forma, boicotando a ideia de consolidação urbana pelo aproveitamento de lotes que não cumprem sua função social.

Além desses três instrumentos, o PDOT autoriza a utilização de outros instrumentos jurídicos que podem servir para a viabilização da execução de programas e projetos habitacionais de interesse social. Assim, temos: (1) o Direito de Preempção, no qual o Estado tem a preferência para aquisição de imóvel objeto de alienação entre particulares, o que pode garantir áreas de interesse estratégico 
para a inserção de moradia social; (2) a Outorga Onerosa do Direito de Construir - ODIR, quando é permitida a construção de edificações superando o coeficiente básico de construção definido para o lote até o limite do seu coeficiente máximo de construção; (3) a Alteração de Uso - ONALT, quando é permitida a mudança de uso do solo. Nesses dois últimos instrumentos é possível que as contrapartidas dos particulares se deem na forma de doação de unidades habitacionais de interesse social ou ainda, que os recursos auferidos em outras formas de contrapartidas também sejam utilizados na execução de programas e projetos habitacionais de interesse social; (4) a Transferência do Direito de Construir, que pode ser utilizada para viabilizar programas de regularização fundiária, urbanização de áreas ocupadas por população de baixa renda e habitação de interesse social; e (5) a Operação Urbana Consorciada, permitida para implantação de programas de habitação de interesse social.

Desses instrumentos, os que mais ocorrem no Distrito Federal são a ODIR e a ONALT, sendo que, conforme destaca Azevedo (2014), os recursos levantados, quando em pecúnia, deverão ser revertidos ao Fundo de Desenvolvimento Urbano - FUNDURB ( $L C n^{\circ} 800 / 2009$ ), vinculado à SEDUH e criado para viabilizar projetos e programas de desenvolvimento urbano. Os demais instrumentos não são aplicados, embora pudessem auxiliar em muito aos programas de habitação social no DF.

Figura 4: Mapa de estratégias de regularização fundiária e de oferta de áreas habitacionais no DF



Fonte: GDF, PDOT/DF, 2012

\subsection{As ZEIS e o PMCMV no Distrito Federal}

O Programa Minha Casa Minha Vida - PMCMV, regulamentado pela Lei Federal $\mathrm{n}^{\circ}$. 11.977, de 7 de julho de 2009, surgiu com a finalidade de promover habitação para famílias com renda de até 10 salários mínimos, trabalhando para a diminuição do déficit habitacional no Brasil. Em Brasília, no âmbito da Política Habitacional implementada por meio da Lei № 3.877 de 26 de junho de 2006, foi 
lançado o Programa Morar Bem, instaurado como instrumento da política habitacional no DF com a finalidade de assegurar que não existissem falhas na seleção da população que participasse dos processos seletivos de programas habitacionais no DF. Por meio do Morar Bem, as unidades habitacionais são vendidas à população beneficiária através de financiamentos do PMCMV. É prérequisito que os empreendimentos sejam entregues em condições de habitabilidade, em locais com infraestrutura de esgoto, água, asfalto, luz e escritura devidamente registrada.

Mesmo diante dessas exigências, esses empreendimentos são lançados longe do centro da cidade, sem a infraestrutura básica necessária, provocando a necessidade de mais investimento do Governo e mais tempo para a entrega da obra. Observa-se ainda que as áreas onde ocorreram as implantações dos PMCMV no Distrito Federal não são áreas destinadas para ZEIS, com algumas exceções, como é o caso do Setor Habitacional Mangueiral, na Região Administrativa do Jardim Botânico; do Residencial Crixá, em São Sebastião e do Paranoá Parque e Itapoã Parque, no Paranoá. No DF os terrenos são diretamente negociados pelas construtoras, com a participação do Estado ou não, a fim de atender a necessidade de moradia para a população de baixa renda.

A segregação das áreas destinadas para habitação social dificulta o acesso à serviços básicos para a população, como infraestrutura de transporte e abastecimento e rede de serviços públicos essenciais. Em reportagem exibida na GloboNews, em 02/07/2016, foram mostrados os dados onde mais de 2 (duas) mil habitações foram entregues com problemas de infraestrutura. Quanto às instalações públicas, prédios foram ocupados pelos novos moradores até mesmo sem água e sem energia elétrica, além de alguns problemas construtivos.

Existe ainda a preocupação quanto à conectividade das áreas, sendo esta essencial para o combate à exclusão social. No DF observa-se que os critérios locacionais que devem ser obtidos para que a ZEIS de vazio se constituam em reserva de terras sustentáveis nem sempre foram atendidos nas reservas de terra estabelecidas pelo seu PDOT e nem pelas áreas destinadas ao PMCMV. Na maioria dos casos estudados no DF, as áreas não possuem infraestrutura e equipamentos públicos e foram locadas às margens das cidades onde já concentram população de baixa renda, não permitindo assim a diversidade de classes sociais. Como não possuem fácil integração com a malha da cidade já existente, o acesso à infraestrutura é difícil; com parâmetros de inserção urbana inexistentes.

\subsection{As ZEIS e o Programa Habita Brasília}

O Programa Habita Brasília, criado pelo Decreto n`37.438, de 24 de junho de 2016, tem como alguns de seus objetivos, a promoção da diversificação das soluções de moradia e a promoção do uso do espaço urbano, priorizando a implantação de moradias em áreas com infraestrutura e próximas às centralidades urbanas existentes ou previstas. Nesse programa foram desenvolvidos cinco eixos: Lote Legal, Projeto na Medida, Morar Bem, Aluguel Legal e Portas Abertas, os quais são destinados a atender a demanda de moradia de inscritos nas listas da Codhab, responsável pela execução da política habitacional no DF. Dentro do contexto das ZEIS de vazio, iremos nos ater apenas à linha de ação Morar Bem, por se tratar da linha ligada ao PMCMV, que produz unidades habitacionais para a população de baixa renda dentro do Distrito Federal.

Pelo Programa Morar Bem, foram ou estão sendo construídos Conjuntos Habitacionais como o Paranoá Parque, às margens da Cidade do Paranoá e o Itapoã Parque, às margens da Cidade do Itapoã, ambos em áreas de ZEIS previstas pelo PDOT. É importante observar que as áreas elencadas estão próximas a áreas localizadas nas periferias e longe dos postos de trabalho, com vários problemas de serviços, de equipamentos públicos e comunitários e de infraestrutura, principalmente de transporte.

A tipologia adotada para esses conjuntos habitacionais criados pelo Morar Bem, à exemplo do 
PMCMV, sempre similares como podemos observar na Figura 5, remete-se a uma habitação de interesse social inserida em grandes empreendimentos, na forma de condomínios, sem variedade de tipologias e de rendas, trazendo à tona verdadeiros guetos sociais, normalmente carecendo de maior integração com seu entorno. Talvez, o desenvolvimento de modelos mais inseridos no contexto da malha urbana e em menores proporções, tragam melhores resultados e produzam habitações mais sustentáveis no contexto da cidade.

Apesar da tentativa de melhoria da conectividade buscando áreas mais centralizadas, o caso de criação de ZEIS no DF esbarra no problema do espraiamento das cidades e na blindagem do Plano Piloto para com as camadas mais pobres da população.

Figura 5: exemplos de tipologias utilizadas.


Fonte: CODHAB, Relatório de Atividades, 2015

\section{Considerações Finais}

O Estado, por meio de suas práticas de implantação e de intervenção nas ZEIS, tem institucionalizado a segregação socioespacial, negando as possibilidades contidas no referido dispositivo jurídico. Historicamente, as tentativas governamentais de reversão do quadro exposto revelaram-se desastrosas. Sem perder de vista os potenciais encerrados pelas ZEIS que, se bem aproveitados, podem se configurar como espaços permanentes de lutas sociais interestatais, questiona-se, o modo como o dispositivo vem sendo operacionalizado no Distrito Federal em relação às suas potencialidades sociais.

Nesse sentido, fica claro que as ações estatais não contribuíram para a reversão radical do quadro de segregação socioespacial verificado em uma cidade do porte de Brasília. Ao contrário, as intervenções têm desencadeado processos que são, em última análise, a negação da existência do princípio que norteia a institucionalização das ZEIS. Na verdade, ocorre a institucionalização da segregação socioespacial refletida, sobretudo, na continuidade dos processos de periferização dos mais pobres e do aproveitamento eleitoral da situação de pobreza urbana. 
Trata-se da perpetuação dos estigmas e preconceitos já existentes, na permanência das marcas de precariedade infra estrutural dos referidos espaços e na subserviência aos ditames impostos pelo capital imobiliário. A utilização da ZEIS de vazios em áreas centrais das diversas Regiões Administrativas - RAs do Distrito Federal poderiam melhorar significativamente o quadro de segregação social vislumbrado na Capital Federal ao alocar as famílias alvo dos programas de Habitação de Interesse Social - HIS próximas dos seus locais de trabalho e de laços familiares e afetivos.

A demarcação das ZEIS de vazios é de suma importância para assegurar e ampliar a destinação de terras bem localizadas e com infraestrutura para a população de baixa renda, criando uma reserva de mercado de terras para a produção de habitação de interesse social e evitando mecanismos que impeçam a posterior expulsão dos núcleos ocupados por segmentos sociais de maior poder econômico, atraídos pela valorização desses terrenos. Em Brasília, considerando todas as áreas possíveis de se transformar em ZEIS vazias dispostas no PDOT somada às áreas indicadas pela TERRACAP para o Programa Habita Brasília são suficientes para fornecer atendimento à demanda habitacional, mas não são capazes de proporcionar o acesso à cidade às famílias de baixa renda na sua integralidade.

Considerando as áreas vazias definidas pelo PDOT, avança-se no sentido de delimitar as áreas para provimentos de moradia. No entanto, observa-se que as áreas vazias possuem, quase na sua totalidade, características locacionais fora do contexto definido pela legislação, primando pela continuidade da segregação socioespacial e consolidando as áreas para a população de baixa renda distantes do local de concentração de oferta de trabalho (Plano Piloto). Já as áreas do Programa Habita Brasília apresentam uma melhor conectividade com o tecido urbano já existente, permitindo uma menor segregação, uma melhor inserção e maior aproveitamento da infraestrutura já presente dentro da Administração Regional a qual a área está inserida.

É importante ressaltar a importância do estudo das áreas a fim de balizar políticas, planos e projetos relacionados à habitação social, verificando a eficácia no atendimento ao qual uma ZEIS de vazios se propõe. Mesmo as áreas do Habita Brasília sendo melhor integradas, o problema da distância ao maior centro de trabalhos, o Plano Piloto, ainda persiste.

Os avanços na legislação voltadas para as políticas habitacionais de nada adianta se o Estado não agir no enfrentamento dos interesses hegemônicos. É preciso se voltar às necessidades básicas da população, buscando uma cidade mais integrada tanto social quanto espacialmente. A blindagem do Plano Piloto perante às camadas mais pobres da sociedade é uma barreira difícil a ser rompida, mas não impossível. Essa forma de exclusão social e urbana precisa ser repensada.

Observa-se ainda a importância de não ignorar outros instrumentos urbanísticos disponibilizados pelo Estatuto das Cidades que, associados às regras das ZEIS de vazios e com a mediação do poder público, poderiam servir para complementar e viabilizar a política de habitação de interesse social abrangendo os diversos interesses envolvidos (proprietários, empresários e beneficiários). Talvez esse modelo pudesse ser exemplo e, como tal, replicado às demais cidades brasileiras que possuem os mesmos problemas sociais. Importante ressaltar que, como a maioria dos Planos de Ordenamento Territorial não previu esse tipo de articulação, elas deverão ser contempladas posteriormente, por meio de outras regulamentações.

Mas porque isso não ocorre, uma vez que existem as áreas vazias de ocupação, muitas vezes em lotes de propriedade do próprio governo, que poderiam ser disponibilizados sem maiores dificuldades a essas famílias? Qual o impeditivo então? Vontade política? Incompetência estatal? Poderio do 
mercado imobiliário que deseja reserva de mercado? Preconceito da sociedade que não permite pobres nos centros urbanos? Essa é uma reflexão que deve ser realizada, com vistas a entender mais profundamente nossa sociedade e como alterar essas mazelas sociais, antes que estas acabem por destruir a própria sociedade que a cria e ignora.

\section{Referências}

AZEVEDO, Heloisa. et al. Instrumentos Urbanísticos, Jurídicos e Tributários para o Desenvolvimento Urbano - Uma Análise da Sua Implantação no Distrito Federal. Texto para Discussão n. 1962. Rio de Janeiro: IPEA, 2014. Disponível em: http://repositorio.ipea.gov.br/bitstream/11058/3111/1/TD_1962.pdf. Acesso em 30 jan. 2018.

BITOUN, Jan; MIRANDA, Lívia. Estrutura espacial da diferenciação sócio-ocupacional na região metropolitana do Recife 1980-2000. In: RIBEIRO, Luiz C. de Q. (org.). Metrópoles: entre a coesão e a fragmentação, a cooperação e o conflito. São Paulo: Fundação Perseu Abramo, 2004.

BRASIL. Estatuto da Cidade. Lei $n^{\circ} 10.257$, de julho de 2001, que regulamenta os arts. 182 e 183 da Constituição Federal, estabelece diretrizes gerais da política urbana e dá outras providências. Brasília, 2001.

BRASIL. Lei n 11.977 de 7 de julho de 2009. Dispõe sobre o PMCMV e a Regularização Fundiária de Assentamentos urbanos. Brasília, 2009.

CÂMARA DOS DEPUTADOS DO BRASIL. 2001. Estatuto da Cidade: Guia para implementação pelos municípios e cidadãos. Brasília: Centro de Documentação e Informação. Coordenação de Publicações.

CAMPOS, Neio Lúcio. A produção da segregação residencial em cidade planejada. Dissertação (Mestrado)-Universidade de Brasília - UnB. Brasília, 1988.

CARDOSO, Lúcio Adauto; ARAGÃO, Thêmis Amorim. Do fim do BNH ao Programa Minha Casa, Minha Vida. In: CARDOSO, Lúcio Adauto (org.). O Programa Minha Casa, Minha Vida e seus efeitos territoriais. Rio de Janeiro: Letra Capital, 2013.

CASTELLS, Manuel. La cuestión urbana. México: Siglo XXI, 1978.

COMPANHIA DE DESENVOLVIMENTO HABITACIONAL DO DISTRITO FEDERAL. CODHAB usa o georreferenciamento para detalhar perfil de habitação no DF. CODHAB: Brasília, 2015. Disponível em: http://www.codhab.df.gov.br/postagem/4. Acesso em: 25 jan. 2020.

COMPANHIA DE DESENVOLVIMENTO HABITACIONAL DO DISTRITO FEDERAL. Relatório de Ativ idades -

2015. CODHAB: Brasília, 2015b. Disponível em: http://www.codhab.df.gov.br/uploads/archive/files/5e2 b27abe3313fa1d9b244674eb98934.pdf . Acessado em: 25 jan. 2019

CORRÊA, Roberto Lobato. O espaço urbano. São Paulo: Ática, 2005.

CRUZ, Natália M. Inclusão e exclusão na nova capital. Revista Brasiliense de Pósgraduação em Ciências Sociais, Brasília, ano v, p. 79-97, 2001.

DISTRITO FEDERAL. Lei Complementar no 803, de 25 de abril de 2009 - Aprova a revisão do Plano Diretor de Ordenamento Territorial do Distrito Federal - PDOT. Brasília, 2009. Disponível em: http://www.seduh.df.gov.br/wpconteudo/uploads/2017/09/1at_Icdf_00803_2009_atualizada_Ic854_2012_sem-anexos-1.pdf. Acesso em: 13 jan. 2019.

DISTRITO FEDERAL. Lei Complementar ํo 854, de 11 de outubro de 2012- Atualiza a Lei Complementar o 803, de 25 de abril de 2009. Brasília, 2009. Disponível em: http://www.seduh.df.gov.br/wp-conteudo/uploads/2017/09/lc_854_15102012.pdf. Acesso em: 13 jan. 2019. 
DISTRITO FEDERAL.Plano Distrital de Habitação de Interesse Social, Plandhis.Brasília:GDF,2012. Disponível em: http://www.seduh.df.gov.br/wp-conteudo/uploads/2017/10/PLANDHIS-

Reda\%C3\%A7\%C3\%A3o-final-12.12.12.pdf. Acesso em 17 jan. 2019.

FUNDAÇÃO JOÃO PINHEIRO. Déficit habitacional no Brasil 2015. Belo Horizonte: Fundação João Pinheiro, 2017.

GLOBONEWS. Mais de 2 mil apartamentos do programa Morar Bem são entregues com problemas no DF. Disponível em: http://g1.globo.com/globo-news/jornal-globo-news/videos/v/mais-de-2-milapartamentos-do-programa-morar-bem-sao-entregues-com-problemas-no-df/5136054/\#. Acesso em 15 jan. 2019.

GOUVÊA, Luiz Alberto de Campos. Brasília: a capital da segregação e do controle social - uma avaliação da ação governamental na área da habitação. São Paulo: Annablume, 1995.

HARVEY, David. Valor de uso, valor de cambio y teoria de la utilización del suelo urbano. In: Urbanismo y Desigualdad Social. Madrid: Siglo XXI, 1977.

LEFÉBVRE, Henri. O direito à cidade. Tradução Rubens Eduardo Frias. São Paulo: Centauro, 2001.

LOSTÃO, Salvador Soler. O Prezeis: um processo de participação popular na formação da cidade. 1991. Dissertação (Mestrado em Desenvolvimento Urbano) - Faculdade de Arquitetura e Urbanismo, Universidade Federal de Pernambuco, Recife, 1991.

MARICATO, Erminia. Brasil, cidades: alternativas para a crise urbana. Rio de Janeiro: Vozes, 2011.

MELLO, C.M.C e BEZERRA, M.C.L. O Papel dos instrumentos urbanísticos na promoção da sustentabilidade da habitação de interesse social no Brasil. ANAIS do $5^{\circ}$ Simpósio Sobre Sistemas Sustentáveis. pg. 140 a 147. Porto Alegre, 2019.

MORAES, Luciana Rocha de. Meio cheio, meio vazio: uma análise dos vazios urbanos de Brasília. 2018. Dissertação (Mestrado em Arquitetura e Urbanismo) - Universidade de Brasília, Brasília, 2018.

MINISTÉRIO DAS CIDADES. Como delimitar e regulamentar Zonas Especiais de Interesse Social. ZEIS de Vazios Urbanos. Brasília, 2009.

MIRANDA, Lívia; MORAES, Demóstenes. O Plano de Regularização das Zonas Especiais de Interesse Social (Prezeis), in Cardoso, Adauto L. (coord.) Habitação Social nas Metrópoles Brasileiras. Programa Habitare, FINEP, ANTAC. Porto Alegre, 2007.

PAULA, Raquel F. M. Permanência e Fissuras: ZEIS vazias na experiencia recente da política habitacional de Belo Horizonte. 2019.Dissertação (Mestrado em Arquitetura e Urbanismo) Universidade de Brasília, Brasília, 2018.

PELUSO, Marilia Luíza. Brasília: do mito ao plano, da cidade sonhada à cidade administrativa. Revista Espaço \& Geografia. Brasília, v. 6, n.2, 2003, p. 1-29

SANTORO, Paula Freire. BORRELLI, Júlia. Os desafios de produzir habitação de interesse social em São Paulo: da reserva de terra no zoneamento às contrapartidas obtidas a partir do desenvolvimento imobiliário ou das ZEIS à Cota de Solidariedade. In: XVI Encontro Nacional da ANPUR. Belo Horizonte, 2015.

SAULE JÚNIOR, Nelson. A proteção jurídica nos assentamentos irregulares. Porto Alegre: Sérgio Antônio Fabris Editor, 2004.

SECRETARIA DE GESTÃO DO TERRITÓRIO E HABITAÇÃO. Zonas Especiais de Interesse Social para provimento habitacional: Estudo de proposição. Caderno de ZEIS. Brasília: SEGETH, 2017. 
SECRETARIA DE ESTADO DE DESENVOLVIMENTO URBANO E HABITAÇÃO. Geoportal. Brasília: SEDUH, 2019. Disponível em: https://www.geoportal.seduh.df.gov.br/mapa/. Acessado em: 13 jan. 2019.

SILVA, M.; VASCONCELOS FILHO, J. M. Revista FORMAÇÃO (Online) Vol. 3; n. 23; maio/ago.2016; p. 50-73. Acessado em 15 dez. 2018.

VILLAÇA, Flávio. Espaço Intra-Urbano no Brasil. Studio Nobel: São Paulo, 2001 